\title{
Impact of Noise on Health: The Divide between Policy and Science
}

\author{
Arline L. Bronzaft \\ Professor Emerita, City University of New York, New York, NY, USA \\ Email: albtor@aol.com
}

How to cite this paper: Bronzaft, A.L. (2017) Impact of Noise on Health: The Divide between Policy and Science. Open Journal of Social Sciences, 5, 108-120. https://doi.org/10.4236/jss.2017.55008

Received: March 20, 2017

Accepted: May 9, 2017

Published: May 12, 2017

Copyright (C) 2017 by author and Scientific Research Publishing Inc. This work is licensed under the Creative Commons Attribution International License (CC BY 4.0).

http://creativecommons.org/licenses/by/4.0/

\begin{abstract}
In her chapter "Sources of Noise" in Noise and Health, Annette Zaner [1] writes that sounds have been environmental pollutants for thousands of years, citing examples of stories of loud music in the Old Testament and noisy delivery wagons in ancient times. The Industrial Revolution and urbanization in more recent times raised the decibel levels in our communities, especially with the growth in transportation on the roads, on the rails and in the air, as well as the growth of noise polluting products. The proliferation of boom cars, cell phones and wind turbines during the past twenty years has made our world even noisier. Studies have been carried out that have demonstrated the potential impact of these noises on our mental and physical health, and there have been some efforts to lessen some of the intrusive sounds, e.g. aircraft and road traffic noise, but there is still too little attention paid to the deleterious effects of noise. While noise complaints top the list of complaints in major cities worldwide and noise even threatens the natural sound systems of our planet, there is no movement globally to address the noise pollutant. The following paper will examine the research linking noise to health effects, question why governments have not seriously attempted to lower noise levels and suggest ways to lessen the din. Doing so will not only be beneficial to our health and well-being but it would also be wise economically.
\end{abstract}

\section{Keywords}

Noise Pollution, Noise and Health, Noise and Public Policy

\section{Introduction}

Noise has been defined as an unwanted, uncontrollable and unpredictable sound that disturbs and annoys an individual. With this definition, there has been a tendency to view noise as an annoyance and, secondly, as a sound that is deemed annoying to an individual on a personal level. Thus, it has been said that one 
person's music is another person's noise. Viewing noise as personal to the listener and as simply annoying has resulted in ignoring the potential harm of this pollutant. However, a growing body of research has sufficiently demonstrated that noise is more than annoying-it is a mental and physical health hazard. Furthermore, while there may be some people who are less impacted by intrusive sounds and some who are very much disturbed by surrounding sounds, we find that the larger number of people in the middle range of the normal curve is indeed affected by transportation noises, construction noises, community noises, and neighbor noises. This paper will identify the research linking noise to adverse health impacts and, hopefully, it will persuade readers to reach out to their public officials to introduce policies to lessen the surrounding noises for the sake of the well-being of all people.

\subsection{Noise: A Longtime Pollutant Calling Out for Attention}

When Pope Francis, in his visit to the United States several years ago, stood outside Independence Hall in Philadelphia to deliver a resounding message in his soft voice to millions of people both standing before him in person and listening via the media, he reminded all of us that a powerful message need not be accompanied by a loud voice. In his talk, he mentioned the wise men that met and wrote the United States Constitution in that same building in May 1787. However, I doubt that the Pope knew that these men asked to be surrounded by quiet as they set down the principles by which this newly found nation would be governed.

"Freshly spread dirt covered the cobblestone street in front of the Pennsylvania State House, protecting the men inside from the sound of passing carriages and carts." (Http://www.barefootsworld.net/consti15.html).

Noises indeed would have intruded upon their thinking, their interactions and their deliberations. Possibly, the individuals, shaping American policy today on noise, or for that matter any of the issues being addressed in Congress, are failing to move our country forward on these issues because they don't understand that loud talking and shouting intrude on thoughtfulness and wise decisions. Shouting may have catapulted President Donald Trump to the Presidency, and, apparently, he still believes speaking loudly carries clout. Will he learn, and hopefully soon, that better decisions are forged when voices are lowered?

As Annette Zaner notes in her chapter on Sources of Noise in Noise and Health [1], loud sounds have been environmental pollutants for thousands of years, citing examples of noisy delivery wagons in ancient times and stories of loud music in the Old Testament. She states that in recent times, from the end of the 19th century into the 20th century, the Industrial Revolution and urbanization raised the decibel level in our communities, especially with the growth in transportation on the roads, on the rails and in the air, as well as the growth of noise polluting products. In the mid $20^{\text {th }}$ century in the United States, there were efforts in some cities to reduce noise impacts, e.g. New York City. However, it was the passage of the Noise Control Act in 1972 and the establishment of the 
Office of Noise and Abatement (ONAC) in the US Environmental Protection Agency (EPA) that made noise abatement a national issue. This office was mandated to develop programs to educate people to the dangers of noise and to inform them of ways to reduce noise in their lives. ONAC also assisted state governments with their noise reduction efforts. While acknowledging that additional research was needed to strengthen the link between noise and health effects, the United States' position was best reflected in the statement made by Dr. William H. Stewart, former Surgeon General, in his keynote address to the 1969 Conference on Noise as a Public Health Hazard:

"Must we wait until we prove every link in the chain of causation? I stand firmly with Surgeon General Burney's statement of 10 years ago. In protecting health absolute proof comes late. To wait for it is to invite disaster or to prolong suffering unnecessarily."

US EPA “Noise: A Health Problem. Office of Noise Abatement and Control, August 1978 [2]

Additionally, Russell Train, the administrator of EPA, in a 1976 talk on aircraft noise, stated:

"It is time for all to come together, and to come to grips with the problem of aviation noise, and to build, at long last, an air transportation system that is safe, healthy, and quieter."

US EPA “Aviation Noise: Let's get on with the job. April 1976 [3].

Then Ronald Reagan became President in 1981 and he essentially closed down the Office of Noise Abatement and Control in US EPA. He and his EPA administrator Anne Gorsuch declared that it was best to deal with noise issues at the state level, even though at that time many of the states depended on federal funding and direction for its anti-noise efforts. While the federal government still oversees noise abatement in some areas, e.g. noise in the workplace, the agency deemed to oversee the Noise Control Act, namely the US EPA, essentially disbanded its noise activities. Speaking to the closing of the Office of Noise and Abatement under former President Reagan, the then Noise Manager of Oregon, Terry Obteska, wrote: "The demise of the federal program in 1981 has been a disastrous experiment, resulting in the wholesale death of state and local programs [4]." Sidney Shapiro who solicited Mr. Obteska's comments, as well as similar responses from other state environmentalist heads, wrote in his report "The Dormant Noise Control Act [4]" that the decision to defund the Office of Noise Control and Abatement signaled to the states that noise was not important. Thus, noise was now seen as a "nuisance," a condition that could be handled by adaptation.

President Reagan was followed by both Democratic and Republican Presidents who have similarly shown no interest in curbing noise. Neither has Congress these past twenty years. Why? One explanation might be that ONAC was to initiate a Buy Quiet program which would have asked industry to lower the decibel levels of their products, e.g. home appliances, construction equipment, etc. and while industry at some future date did indeed lower the decibel levels of 
such products, it is possible that in 1981 they determined that they would rather quiet their products at their own pace without government intrusion. I believe that government decisions are still influenced by corporations and the "noise making" companies would rather deal with the issue on their own terms, rather than have the government oversee their actions.

Listening to a speech that President Barack Obama gave to Congress, early in his first term, I thought his administration might demonstrate an interest in the noise issue. He spoke of a school he visited in Dillon, South Carolina as a place where they had "...to stop six times a day because the train barrels by their classroom." As he made this statement, he pointed to a student from that school, Ty'Oshema Bethea, who was sitting next to his wife. I hoped his comment would lead him to do something about noise in the schools, a topic I have researched and written on, but to my disappointment, the words he used in that speech were largely uttered to draw attention to the student he invited to his talk. I later learned that the school the President visited did receive local funding that addressed the leaks, the peeling paint and, hopefully, the noise.

Now that Donald Trump is President of the United States, one could ask what role will the federal government play in lessening the impacts of noise on health, in light of the fact that the Noise Control Act passed in 1972, is still in effect. That act was passed to "...promote an environment for all Americans free from noise that jeopardizes their health and welfare." Recognizing that the US EPA has essentially ignored the Noise Control Act for the past thirty-five years, one could still wonder about the attitude of a new administration toward noise pollution, especially since President Trump has been combating aircraft noise over his Florida estate for over twenty years including a 2015 lawsuit seeking damages for "creating an unreasonable amount of noise [5]."

A visit to the US Environmental Protection Agency's (EPA) first page today does not list any reference to noise as an environmental pollutant. One has to click into several sections to access information on noise and its effects and in one of the sections accessed, noise pollution is linked to the Clean Air Act, as if the Noise Control Act never stood on its own. Further exploration of EPA's interest in noise will yield a page that states that the Noise Control Act has not been rescinded; it is inactive. In other words, The United States passes laws but they don't have to be enforced.

When one does find some information on the adverse effects of noise on health, the research and studies cited are not recent; thus, omitting research that more strongly linking noise to health effects that have been conducted in the past five years. There is on the site a large publication dating back to the 1970s that is identified as "Foreign Noise Research in Noise Effects: a Survey of Foreign Noise Effects Research. Highlighting a publication as only containing foreign research raises the question of the applicability of the findings to Americans. That EPA will undoubtedly continue to ignore the deleterious impacts of noise is not unexpected in light of the fact that the head of the EPA, Scott Pruitt, has been critical of the agency for many years. This view is strengthened by the 
recent New York Times article [6] which noted: "Reports last week that the administration is proposing deep budget cuts for government agencies including...and the Environmental Protection Agency have fueled new fears of databases being axed..."

With the loss of the Office of Noise Abatement and Control (ONAC) these past thirty plus years, citizens in the U.S., especially those exposed to aircraft noise, have had no federal agency to advocate lessening the noise in their communities. Although the Federal Aviation Administration oversaw aircraft noise, ONAC could provide pressure on this agency by statements, as noted above, that aircraft noise had an adverse impact on health. Noise continued to be a more pressing problem as the years passed and citizen groups were formed throughout the United States to combat this pollutant. Working with citizens in the New York region, Congresswoman Nita Lowey introduced a bill in the House of Representatives in 1997 to refund ONAC, as did Senator Robert Torrecelli in the Senate. While they were able to gather forty-five sponsors in the House and four in the Senate, their bills did not pass. Congresswoman Lowey attempted to introduce her legislation to refund ONAC in 1999 and 2005 but to no avail.

\subsection{Noise: Still a Viable Pollutant}

Today in 2017 the most vocal spokespersons for abating noise belong to these groups across the country who have been adversely impacted by intrusive noises, especially those living near airports. Several of these groups are calling for their Congresspersons to roll back the Federal Aviation Administration's program aimed to improve air travel because the agency has not paid close enough attention to the noise incurred by restructuring the air routes. In 2016 Congresswoman Grace Meng of New York City, joined by several colleagues in other states, has introduced legislation, similar to that supported by the Congresswoman in 1997, to give the federal government a voice in lessening noise, especially that of aircraft. In the Senate, Senators Schumer and Gillibrand introduced a comparable bill. Congresspersons in Arizona, California, Florida, New York, etc. have introduced legislation to give local communities a greater role regarding flight paths because residents are being exposed to unacceptable levels of aviation noise. However, bills introduced by Congress people have to be voted on to become law and while citizen groups are hopeful that the federal government will eventually become concerned about noise impacts, in my opinion, the turmoil in Washington today casts doubt on that optimism.

In speaking against a proposal to build noise barriers along busy highways, the Chair of the Transportation Committee, Bill Shuster stated: "If a homebuilder is willing to build his home next to a highway or an airport, they know what the consequences are [7]." Such comments only underscore the unlikelihood of legislation that would curb noise of residents living near highways or airports or the refunding of the Office of Noise Abatement and Control in the Environmental Protection Agency. 


\section{Is Noise Really A Health Hazard?}

Yet, the literature supporting the adverse effects of noise on mental and physical health has grown in the last fifteen years, underscoring the need to move ahead with federal noise legislation [8] [9] [10]. However, while there have been a few American papers, more of the research has taken place in Europe. Interestingly, the US Federal Aviation Administration Office of Environment and Energy funded a paper entitled "A Review of the Literature Related to Potential Health Effects of Aircraft Noise [11]" in which its author Hales Swift states: “...there are also questions as to whether the results are directly transferable from a collection of European populations to an American one." This statement is repeated a second time in this Review. While I understand that studies have to be replicated, I don't believe that in our global society, we should wonder whether Americans respond differently to noise than do Europeans. Do we bring in comparisons amongst different nations when we discuss causes or treatments of diseases? Thus, with the United States hesitant to generalize noise impacts on health and well-being from European findings, this paper can safely conclude as follows:

"A great deal of research remains to be done in the field of health effects of noise."

Thus, without additional research, the federal government might feel justified in taking it "slow" when it comes to noise abatement, especially with respect to airport-related noise.

To be fair to the Federal Aviation Administration, it did support the Correia, et al study [9] cited above which found “...a statistically significant association between exposure to aircraft noise and risk of hospitalization for cardiovascular diseases among older people living near airports." The Transportation Research Board, a program of the National Academies of Sciences, Engineering and Medicine, devoted its September-October 2015 magazine (TRB, Number 299) to Public Health and Transportation. The first article by Dannenberg and Sener in that issue, "Why Public Health and Transportation: Setting the Stage [12]," states that "...noise can contribute to adverse health effects, including sleep disturbance, hearing loss, and decreased performance. "The article then suggests policies that could lessen impacts of noise on nearby populations: “...changing airport runway use patterns, flight path locations, and hours of operation." With a study on six million older residents that found a relationship between aircraft noise and cardiovascular disease, and an article in a journal funded by state and federal agencies that acknowledges the harmful effects of noise on nearby populations, one could hope that in the near future United States policy decisions will be influenced by scientific findings on the deleterious effects of noise. So far, there has been a divide between research and policy in the United States when it comes to noise impacts. This statement is supported by a Hammer, et al. paper [13] which notes that while "...tens of millions of Americans suffer from a range of adverse health outcomes due to noise exposure," there is not yet "... a national plan to reduce environmental noise pollution." 


\section{Are We Sure Noise Is Harmful to Health?}

The United States is not alone when it comes to determining whether research findings directly impact policy decisions. This is especially true with the recently identified noise intrusion that has received much attention worldwide-noise from wind turbines. In the search for alternative sources of energy, it was with enthusiasm that public officials and environmentalists worldwide have welcomed the possibility of wind as a viable alternative to fossil fuels. Wind turbines were erected in communities in the United States, Canada, Europe and Australia. Then, reports started coming in that residents living near these newly erected turbines were complaining about headaches and loss of sleep. Interestingly, the first response from industry and government was that these people were imagining these impacts.

When Dr. Nina Pierpont [14] wrote her book reporting her findings of vertigo, dizziness, sleep disturbance and other physiological disturbances in a group of 38 residents living near wind turbines, she was widely criticized for her very limited, less than scientific study. Dr. Pierpont's study calls for replication but it should not have been dismissed. In science we start with exploratory research on small numbers and then we move on to studies with larger numbers and greater control of the variables. For example, in the New York Times article on December $15^{\text {th }} 2016$ [15], entitled "Your Brain Versus 'Harold", the author reports on a study relating fitness to thinking in older people that had been conducted on sixty older men. The article indicates that further research is needed but still gives credence to the results reported. One obvious shortcoming of the study is that it only included male subjects but the author of this article in the introductory paragraph generalizes the findings to all “...older people.” The New York Times in its Tuesday Science section frequently reports findings of studies with small numbers and less than ideal control as does the mass media. The findings of these studies are suggestive, although treated more seriously in the media, and should lead to further research. Dr, Pierpont's study should also be a call for additional research exploring the relationship between wind turbine sounds and visual effects and health impacts.

In chapter 5 of Why Noise Matters [8] there is a discussion of several studies that have found that people get more annoyed by wind turbines than noise from road traffic and other industrial sounds. Why Noise Matters concludes that noise need not stop the development of onshore wind turbines, especially if carefully located, but unless the noise issue is seriously addressed, it will harm people and curb the development. Garret Keiser in his book The Unwanted Sound of Everything [16] states that the "...noise effects of wind turbines have been routinely denied by ignorant or unscrupulous developers," supporting his conclusion with studies affirming this statement as well as his experiences personally visiting residents in Maine who described to him the impacts that nearby wind turbines had on their lives.

Acknowledging the fact that a growing number of individuals and organizations have expressed concern about the impact of noise from wind turbines on 
residents living nearby, the Government of Canada, through its Minister of Health asked the Council of Canadian academies to conduct an assessment of the research that has examined the association between exposure to wind turbine noise and adverse health effects. A panel of experts from Canada and other countries worldwide was set up to evaluate the evidence linking health impacts of wind turbine noise and to identify research gaps as well. The Council of Canadian Academies issued its report "Understanding the Evidence: Wind Turbine Noise" in the Spring of 2015 (www.scienceadvice.ca). The Executive Summary found sufficient evidence between exposure to wind turbine and annoyance, limited evidence to support a relationship between exposure to wind turbine noise and sleep disturbance, inadequate evidence to support link between wind turbine noise and stress and found inadequate evidence to conclude the presence or absence of a relationship between other health effects and wind turbine noise. Recognizing that chronic exposure to other sources of noise, e.g. air and road, have led to stress responses and in turn to risk factors for cardiovascular disease, the Panel found that "...available evidence does not allow conclusions with regard to the prevalence of annoyance or other health effects." The Panel also recognized that A-weighted measurements which have been commonly used to assess potential impact of wind turbine noise on residents may "...fail to capture the low frequency components of wind turbine sound." This failure to include low-frequency measurements in determining impacts of wind turbine sounds was considered a shortcoming in determining potential health impacts.

The Canadian report states that Canada is increasingly depending on wind turbines to provide their citizens with electricity. With that in mind, the Panel notes that the health effects of wind turbine noise have rarely been expressed with "...detailed, reproducible and rigorous data sufficient to support a conclusion on either causation or magnitude of any potential health effect." However, in light of the earlier statement above that evidence does not allow a conclusion of absence of a relationship, one might expect a final statement stressing greater caution as Canada moves forward with wind turbine development. Additionally, the statement that: "Community engagement helps to inform and educate local residents, as well as involve them in a wind energy project with the goal of fostering social acceptance" also calls into question whether this report will indeed "...inform decision-making and academic research on the subject" as the Panel hopes it will.

That Canada, like the United States, may not have depended in recent years on scientific findings to determine policy is supported by a New York Times op ed article written by Dr. Wendy Palen of Simon Fraser University [17]. She states that in 2007, shortly after Stephen Harper became Prime Minister, rules were issued that kept federal scientists from discussing their findings with the media. She then goes on to say that these scientists feared retaliation if they spoke up about "...science that affected public health or the environment." She also writes that environmental data were discarded and that the Prime Minister's government passed a bill that "...eliminated or amended our marquee environ- 
mental protection laws." Dr. Palen concludes on a more reassuring note stating that the election of the new Prime Minister Justin Trudeau may “...put scientists” right to speak and the promise of evidence-based decisions alongside job creation and economic growth."

Reading Dr. Palen's essay tends to underscore my conclusion above that the Council of Canadian Academies report on wind turbines night not lead to sound decision making and appropriate academic research. Secondly, Dr. Palen's writings on the actions to weaken environmental protection laws by the Harper government sounded so familiar to what former President Reagan did with respect to the noise arm of US EPA. Thirdly, Dr. Palen warns in her first sentence that President Trump's actions so far do not bode well for science in the United States and in her last sentences she urges American scientists to reject interference and to stay vocal and vigilant. I cannot agree more heartily. So as not to be completely pessimistic that people's responses to a noise source, such as wind turbines, will tend to be ignored, I refer to the action by a Danish municipality to cancel plans for all on shore wind turbines because of the possibility that "...low frequency noise affects health." [18]. One resident in this municipality was quoted as saying: "The politicians have let us citizens come first."

\section{Is Smoking a Health Hazard?}

As a child I suffered from asthma and continue to do so but am pleased to report that I have it under control, thanks to my respiratory inhalers. I knew from the time I was very young that I could not be around people who smoked because of my asthma. As I grew older, I could not attend certain meetings because there was too much cigarette smoke in the meeting rooms. For the most part, I, and others like me, were dismissed by smokers who did not believe their cigarette smoke harmed our health. The cigarette industry, supported by the government, similarly dismissed the harmful effects of secondary smoke and argued that there was insufficient research to support the complaints of the many people who claimed they were made sick by cigarette smoke. Yet, there were thousands upon thousands of people who evidenced through their coughing and discomfort in smoke-filled rooms that cigarette smoke harmed them. Today, one is constantly reminded on television segments that parents who smoke will be damaging the health of their children. Later research confirmed what I and my fellow sufferers knew all along that second-hand smoke is harmful to others. While one might say that the "hard" research was necessary to link cigarette smoke to adverse health impacts, I would say that the numbers of people who complained about cigarette smoke should have clued those in decision-making positions to pay greater attention to these complaints. In general, greater weight should be placed on vocal expressions from individuals about their health status. Even doctors today say that they should listen more attentively to what their patients are saying and not simply limit their evaluations on available standard medical tests. Russell Train, quoted above, in speaking about action to limit noise impacts, said that we should not wait for "every link in the chain of causation" before we act 
because to do so would "invite disaster and prolong suffering unnecessarily." I believe we waited too long to take action on limiting cigarette smoking and I second his comments regarding noise impacts.

\section{Policy Decisions Should Reflect Research Findings}

As a researcher, I do indeed believe that "hard" data are needed in determining what actions should be taken to remedy certain situations, Forty years ago, when a parent in my psychology class asked me to do something to lessen the impact of passing train noise on her child's classroom because she believed it intruded on his learning in that classroom, I responded that we would need some evidence to demonstrate that the noise affected classroom learning. It was the request of this mother that led me to carry out a study on the effects of elevated train noise on learning [19]. When we found that by the sixth grade children exposed to the passing train noise were nearly a year behind in reading compared to children on the quiet side of the school building, we then were able to use the data to abate the train noise by to persuade the Transit Authority to put rubber padding on the tracks adjacent to the school and the Board of Education to acoustically tile the classroom ceilings. A later study [20] found that after the noise abatements were in place, children on both of the sides of the school building were now reading at the same level. These two studies, often spoken of as landmark studies, received wide attention in the media.

During these past thirty plus years a number of studies have also found that noise disrupts student learning and so the link between noise/learning link is indeed stronger. However, should New York City have waited to lessen the noise at Public School 98 after learning the results of my study until the evidence would be stronger to justify action? I still wonder why New York's Transit Authority and Board of Education acted so quickly in abating the train noise's impact on classroom learning. The City could have taken the position that more research was needed. These two studies I conducted on noise and classroom learning were also cited by community groups concerned with nearby aircraft noise adversely affecting classroom learning. Interestingly, their efforts to lessen the impacts of aircraft noise on classroom learning resulted in a million dollar nationwide program in the U.S. to abate noise in classrooms affected by such aircraft. A recent government-sponsored study by Sharp, et al. [21] examined the effect of this sound insulation and found the adverse impacts on learning disappeared after the insulation was in place. Here is another example where research findings resulted in policies that benefitted children and, hopefully, could be cited as demonstrating that we need not conduct endless studies before taking action. However, unfortunately, government agencies today still raise questions about the strength of evidence to support changes in policy, whether it be noise or another adverse pollutant.

John Stewart and his associates took the opportunity following Brexit to write an ebook The Noise Climate-Post Brexit [22] in which they outline ways to alleviate noise from a variety of sources, namely, airport, traffic, community, 
neighbor, piped in music and wind farms. John Stewart and his co-authors, the majority of whom contributed to Why Noise Matters [7], start their latest book from a position that recognizes the deleterious effects of noise on health. The authors then acknowledge that the European Union has taken steps to identify the sources of noise but have not yet acted sufficiently to lessen the noises. Stewart, in a private conversation, stated that the UK can now focus on ways to abate the noise now that it is not tied to EU oversight. He added that he hoped that Prime Minister May would be responsive to the suggestions outlined in their book.

\section{Noise Policy Must Reflect Research that Noise Is a Health Hazard!}

I now conclude that there is an abundance of evidence linking noise to adverse mental and health impacts. I include here vocal complaints from people exposed to noise that have not become part of our larger research and the papers published in academic journals. For thirty years, as a member of GrowNYC, formerly Council on the Environment of New York City, I have received complaints about noise from New York City citizens. Noise is one of the major complaints to our 311 Complaint Line. The people who contact me are not part of a formal study but I believe I am qualified enough to speak to the nature of their complaints and the stress and discomfort they have experienced because of noise intrusions. Yet, actions to alleviate the noises of intrusive sources, e.g. roads, rail, aircraft, wind turbines, construction sites, etc. have lagged behind the research. In a paper I wrote entitled "Abating New York City transit noise:: A matter of will, not way" [23] I described how the knowledge to lessen New York City's transit noise problem exists but the desire to act does not. I firmly believe it is the same with respect to other sources of noise, in that the ways to lessen the noise do exist but the desire to do so does not. In a chapter I wrote for Environmental Toxicants [24], I listed several methods to control noises in apartment buildings, hospitals, in schools and on highways, stating that architects, engineers and developers should be as aware of the acoustical environment of their projects as they are of the visual.

Furthermore, I would argue that cost to abate noise is not the overriding issue that many claim it is in that the cost in not alleviating the noise may be higher. We often do not factor in medical and educational costs in deciding what to do about noise sources. When we speak of the costs of lessening aircraft noise, do we consider the medicals costs of older individuals who are being admitted to cardiovascular units because of the impacts of overhead aircraft? When we speak of costs to lessen noises within schools, are we factoring in educational costs of children who have fallen behind in reading because of noisy classrooms? Do we not already know how to design restaurants so that the interior sounds are less offensive, leading many potential customers, especially older people, to avoid the "noisy" venues. Are very loud restaurants really good for business? 


\section{Conclusion}

I have frequently written about my younger daughter's reaction to her mother conducting research on the effects of noise on classroom learning. She, only eight then, thought it was obvious that children could not learn in a noisy classroom. Her mother explained that she would have to look at the children's reading scores to find out if the noise actually interfered with learning in order to justify requesting ways to decrease the noise. Yes, I had to explain to this child why data were necessary to support changes. Now over forty years later, she observes out that her mother is still overseeing a federal study on noise impacts in the classroom and writing on the adverse effects of noise on health and she is utterly bewildered. I, too, am astonished that I am still writing to urge people to lessen the din in their lives in order to protect their health. However, to be fair there are far more people today that support my views than there were forty years ago when I started to write about noise pollution.

Yet, will the outcry from citizens concerned about the deleterious effects of noise on health convince governments to pass policies to address noise pollution? Will public officials recognize that sound data already exist to justify passing and enforcing such policies? I will urge public officials to heed former Surgeon General William H. Stewart's quote noted earlier.

"Must we wait until we prove every link in the chain of causation? I stand firmly with Surgeon General Burney's statement of 10 years ago. In protecting health absolute proof comes late. To wait for it is to invite disaster or to prolong suffering unnecessarily."

\section{References}

[1] Zaner, A. (1991) Definition and Sources of Noise. In: Fay, T.H., Ed., Noise and Health, The New York Academy of Medicine, New York, 1-14.

[2] United States Environmental Protection Agency (1978) Noise: A Health Problem. United States Environmental Protection Agency, Washington DC.

[3] Train, R.E. (1976) Aviation Noise: Let's Get on with the Job. United States Environmental Protection Agency, Washington DC.

[4] Shapiro, S.A. (1991) The Dormant Noise Control Act and Options to Abate Noise Pollution. The Administrative Conference of the United States, Washington DC.

[5] Reid, A. (2016) Trump's Presidential Victory Could Stop Flights over His Palm Beach Estate. Sun Sentinel, 11 November 2016.

[6] Harmon, A. (2017) The Rush to Uncover, and Save "Dark Data". New York Times, 7 March 2017, D1.

[7] Herszenhorn, D.M. (2015) Highway Bill Debate Tests New Speaker's Promise for a More Open House. New York Times, 5 November 2015, A.18.

[8] Stewart, J.S., Bronzaft, A.L., McManus, F., Rodgers, N, and Weedon, V. (2011) Why Noise Matters. Earthscan, London.

[9] Correia, A.W., Peters, J.L, Levy, J.L., Melly, S. and Dominici, F. (2013) Residential Exposure to Aircraft Noise and Hospital Admissions for Cardiovascular Diseases: Multi-Airport Retrospective Study. British Medical Journal, 347, f5561.

https://doi.org/10.1136/bmj.f5561 
[10] Hansell, A.L., Biangiardo, M., Fortunato, L., Floud, S., De Hoogh, K., Fecht, D., et al. (2013) Aircraft Noise and Cardiovascular Disease near Heathrow Airport in London: Small Area Study. British Medical Journal, 347, f5432. https://doi.org/10.1136/bmj.f5432

[11] Swift, H. (2010) A Review of the Literature Related to Potential Health Effects of Aircraft Noise. PARTNER Project 19 Final Report.

[12] Dannenberg, A.L. and Sener, I.N. (2015) Why Public Health and Transportation: Setting the State. TR News, Transportation Research Board, Washington DC, 4-8.

[13] Hammer, M.S., Swiburn, T.K. and Nietzel, R.L. (2014) Environmental Noise Pollution in the United States: Developing an Effective Public Health Response. Environmental Health Perspectives, 122. https://doi.org/10.1289/ehp.1307272

[14] Pierpont, N. (2009) Wind Turbine Syndrome. K-Selected Books, Santa Fe.

[15] Reynolds, G. (2016) Your Brain versus "Harold”. New York Times, 15 December 2016, D8.

[16] Keizer, G. (2010) The Unwanted Sound of Everything We Want. Public Affairs, New York.

[17] Palen, W. (2017) When Canada Muzzled Science. New York Times, 14 February 2017, A27.

[18] Bronzaft, A.L. and McCarthy, D. (1975) The Effect of Elevated Train Noise on Reading Ability. Environment and Behavior, 5, 517-528. https://doi.org/10.1177/001391657500700406

[19] Bronzaft, A.L. (1981) The Effect of a Noise Abatement Program on Reading Ability. Journal of Environmental Psychology, 1, 215-222. https://doi.org/10.1016/S0272-4944(81)80040-0

[20] Ray, W. (2017) Danish Municipality Cancels Plans for all Onshore Wind Turbines. http://cphpost.dk/news/danish-municipality-cancels-plans-for-all-onshore-wind-tu rbines.html

[21] Sharp, B., Connor, T.L., McLauglin, D., Clark, C., Stansfeld, S.A. and Hervey, J. (2014) Assessing Aircraft Noise Conditions Affecting Student Learning. A.C.R. Program, Transportation Research Board of the National Academies.

[22] Stewart, J., Rodgers, N., Thoresby, H., Weedon, V. and McManus, F. (2017) http://hacan.org.uk/wp-content/uploads/2017/02/The-Noise-Climate-Post-Brexit-1 -1.pdf

[23] Bronzaft, A.L. (2010) Abating New York City Transit Noise: A Matter of Will, Not Way. Noise and Health, 12, 1-6. https://doi.org/10.4103/1463-1741.59994

[24] Bronzaft, A.L. (2009) Noise: Its Effects and Control. In: Lippman, M., Ed., Environmental Toxicants. Human Exposures and Their Health Effects, John Wiley \& Sons, New York, 1071-1087. https://doi.org/10.1002/9780470442890.ch28 
Submit or recommend next manuscript to SCIRP and we will provide best service for you:

Accepting pre-submission inquiries through Email, Facebook, LinkedIn, Twitter, etc. A wide selection of journals (inclusive of 9 subjects, more than 200 journals)

Providing 24-hour high-quality service

User-friendly online submission system

Fair and swift peer-review system

Efficient typesetting and proofreading procedure

Display of the result of downloads and visits, as well as the number of cited articles Maximum dissemination of your research work

Submit your manuscript at: http://papersubmission.scirp.org/

Or contact jss@scirp.org 